Yong Jin Shin

Moon Chan Kim

Jin Gu Kang

Hyeon Ung Kim

I Rok Shin

http://dx.doi.org/10.21278/brod70308

ISSN 0007-215X

eISSN 1845-5859

\title{
VALIDATION OF OPTIMALLY DESIGNED STATOR-PROPELLER SYSTEM BY EFD AND CFD
}

UDC 629.5.016.7:629.5.018.71:629.544

Original scientific paper

\begin{abstract}
Summary
The development of energy-saving devices to lower the energy efficiency design index (EEDI) of ships has been actively researched worldwide. One such device is an asymmetric pre-swirl stator, which helps to improve the propulsion efficiency by recovering the rotational energy generated during propeller rotation. Determining the pitch angle is the most important factor in the design of an efficient asymmetric pre-swirl stator. To optimize the pitch angle of an asymmetric pre-swirl stator, this study deals with potential-flow, computational fluid dynamics, and model tests. The model delivered power at a design speed of $24 \mathrm{kt}$ was compared by changing the pitch angle by $\pm 2^{\circ}$ with respect to the reference angle designed using a potential-flow program. The commercial code Star-CCM+ was used for the numerical analysis, and the model was also tested in a towing tank at Pusan National University. This study proposes an effective method for determining and verifying the optimal pitch angle of an asymmetric pre-swirl stator.
\end{abstract}

Key words: $\quad$ asymmetric pre-swirl stator; pitch angle; optimization; model test; computational fluid dynamics (CFD);

\section{Introduction}

International environmental regulations are important to preventing climate change, and regulations against emissions of ships are increasing. The International Maritime Organization is reinforcing regulations that it initiated against $\mathrm{CO}_{2}, \mathrm{NO}_{\mathrm{x}}$, and $\mathrm{SO}_{\mathrm{x}}$, which are representative ship exhaust gases, as the Energy Efficiency Design Index (EEDI), Tier III, and Emission Control Area (ECA) [1]. Accordingly, energy-saving devices have been developed to reduce the EEDI. Energy-saving device development is critical for reducing not only the energy 
Yong Jin Shin,

Moon Chan Kim, Jin Gu Kang

Hyeon Ung Kim, I Rok Shin
Validation of Optimally Designed Stator-Propeller System by EFD and CFD

consumption of ships, but also $\mathrm{CO}_{2}$ emissions. Energy-saving devices are defined for use in three zones, namely, Zones I, II, and III, as shown Fig. 1 [2].

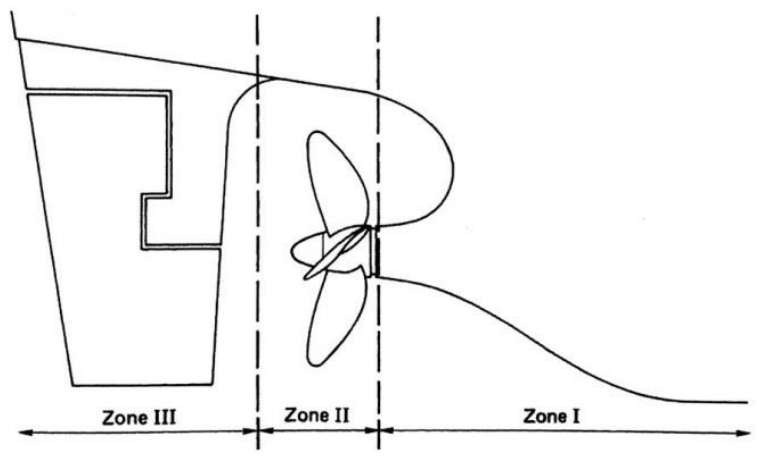

Fig. 1 Zones for the classification of energy-saving devices [2]

These three zones are: I) pre-devices, which are installed toward the bow of the ship, II) main devices, such as propellers, and III) post-propeller devices installed toward the stern of the ship.

Currently, various energy-saving devices are being actively researched. The contrarotating propeller (CRP), a main device, improves propulsion efficiency through recovering rotational energy by installing two propellers rotating in opposite directions on the drive shaft, one facing the front and the other facing the rear. Boucetta and Imine (2019) [3] have been carried out to determine the hydrodynamic characteristics in cavitating viscous flow of the corotating tandem propellers. This paper focuses on the asymmetric pre-swirl stator, because it currently seems to be the most effective device and has been frequently applied without any major problems. A pre-swirl stator, which is a pre-device, improves the propulsion efficiency by recovering the rotational energy generated during propeller rotation via the stator blades placed in front of the propeller. Thus, the pre-swirl stator imposes a flow velocity component against the tangential velocity lost by the propeller and reduces the energy consumption by approximately 4-5\% [4-9]. Moreover, compared to that of a contra-rotating propeller, the shafting of a pre-swirl stator is less complicated, and it is also easier to install. Therefore, the initial installation costs are not only lower, but the risk of breakdown during operation is also reduced [10].

A pre-swirl stator was symmetric and has six blades, as shown in Fig. 2 [11]. Blades at the top and bottom positions appear to be missing; this is intended in consideration of the blockage effects against the on-coming flow and potential-flow docking problems, respectively.

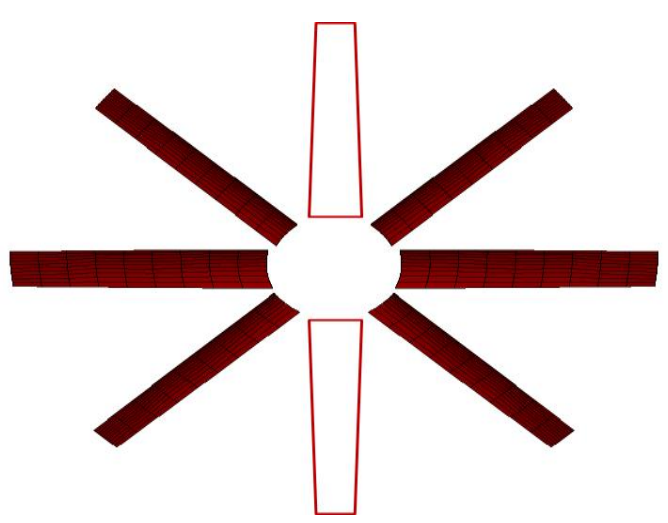

Fig. 2 Profile of Mitsubishi-style reaction fins 
Kim et al. [12] designed and developed an asymmetric pre-swirl stator with three blades on the starboard side and one blade on the port side, as shown in Fig. 3.

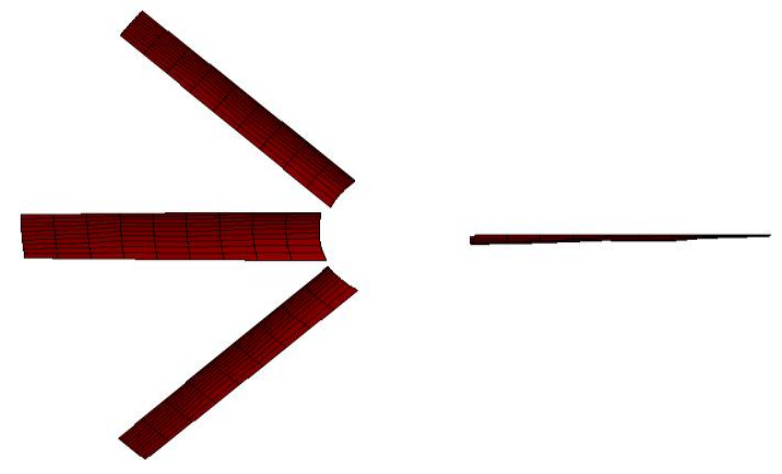

Fig. 3 Profile of an asymmetric pre-swirl stator

The proposed asymmetric pre-swirl stator has fewer blades on the starboard side, as the rotational flow component is different on each side because of the upward flow. The upward velocity is normally cancelled by the propeller rotational velocity on the starboard side, whereas the velocity on the port side is doubled. This phenomenon is evident in the typical velocity vector profile just behind the propeller, which is measured using a laser Doppler velocimeter (LDV) [13]. An asymmetric pre-swirl stator is advantageous compared with the symmetric 6 blades stator because it can not only increase the efficiency by evenly absorbing the rotational energy throughout but can also significantly reduce the manufacturing cost and the load on the stern by removing unnecessary blades. Kim et al. [10] showed that the application of an asymmetric pre-swirl stator to a $300 \mathrm{~K}$ very-large crude oil carrier (VLCC) helped increase the efficiency by approximately 5.6\%. Lee et al. [14] applied pre-swirl stators of the constant-pitch-angle type and variable-pitch-angle type to a $160 \mathrm{~K}$ LNG ship and improved its propulsion efficiency by approximately $6 \%$ and $8 \%$, respectively.

With regard to asymmetric pre-swirl stators, if the pitch angle of the stator in nonuniform wake is identical for each stator, the axial components are non-uniform; moreover, the load on each stator varies significantly because the tangential velocities at the port and starboard sides are opposite to each other with respect to the stator. Therefore, attaining maximum efficiency is difficult unless the pitch angle of the stator at each stator position is adjusted appropriately. Lee et al. [4] used the iterative design method with the lifting surface theory considering the mutually induced velocity of the propeller and pre-swirl stator to determine the pitch angle of an asymmetric pre-swirl stator. They used the Preswirl Asymmetric Stator Analysis (PASTA) program to implement the calculation processes. The lifting-surface code which has been originally developed by Greely and Kerwin(1982) [14] (most popularly used code in propeller field) has been modified by including the stator modeling. The interaction between propeller and stator is considered by iterative scheme and in that case the treatment of stator's wake has to be carefully done. Lee et al. [15] and Shin et al. [16] determined the pitch angle of an asymmetric pre-swirl stator using the PASTA program and found that the efficiency increased by $4-5 \%$. However, the optimal pitch angle corresponding to maximum efficiency needs to be verified.

In the present study, the optimal pitch angle of an asymmetric pre-swirl stator was verified through computational fluid dynamics (CFD) and experimental fluid dynamics (EFD) model tests by changing the pitch angle by $\pm 2^{\circ}$ with respect to the pitch angle determined using the potential-flow program. 
Yong Jin Shin,

Moon Chan Kim, Jin Gu Kang

Hyeon Ung Kim, I Rok Shin

\section{Design of an asymmetric pre-swirl stator}

In the design of the asymmetric pre-swirl stator, a potential-flow-based analysis program was used for the propellers and pre-swirl stators. If the pitch angle of the stator blades is the same for all the blades during non-uniform countercurrents, it is difficult to achieve maximum efficiency without adjusting the pitch angle corresponding to the position of each blade. The stator design has been conducted to have an optimum loading (elliptic loading distribution) for each blade as shown Fig.4.

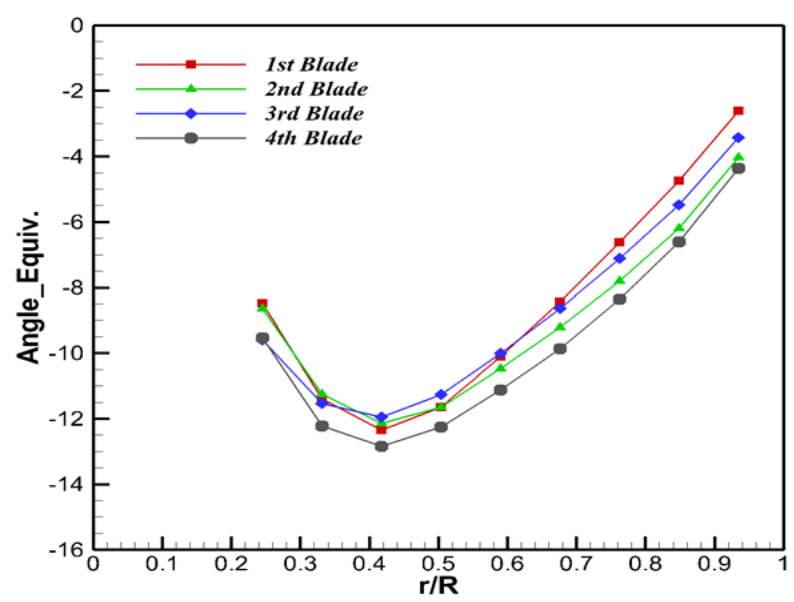

Fig. 4 Example of radial circulation distribution on the stator blades

$\Gamma$ is the circulation strength which indirectly measures the load on the blades; it is used to compare the performance efficiency. In order to relatively compare $\Gamma$, it was nondimensionalized using the radius of the stator blades $(R)$ and design speed $(V \mathrm{~s})$ as shown in Eq.1.

$$
\mathrm{G}=\frac{\Gamma}{2 \pi R V_{S}}
$$

Then, $\Gamma$ was expressed for corresponding $\alpha$ equiv (equivalent angle of attack) to allow for a more intuitive analysis. According to the Kutta-Joukowski theorem, the lift force of a circulating flow is expressed as Eq.2 and the lift coefficient as Eq.3.

$$
\begin{gathered}
\mathrm{L}=\rho \mathrm{V} \Gamma \\
C_{L}=2 \pi \sin \alpha_{\text {equiv. }}
\end{gathered}
$$

Here, $L, C_{L}, C$, and $V$ represent the lift force for the 2D cross section, the lift coefficient, the chord of the cross section, and the inflow velocity, respectively. Conversion of Eq. 3 for equivalent incidence angle and substitution of Eq.1 results in the following Eq.4.

The computed circulation of radial loading in each blade is converted by the equivalent angle of attack ( $\left.\alpha_{\text {equiv. }}\right)$ as introduced in Eq.4. 
Validation of Optimally Designed Stator-Propeller System by EFD and CFD
Yong Jin Shin,

Moon Chan Kim, Jin Gu Kang

Hyeon Ung Kim, I Rok Shin

$$
\begin{array}{r}
\alpha_{\text {equiv. }}=\sin ^{-1}\left(\frac{C_{L}}{2 \pi}\right) \\
=\sin ^{-1}\left(\frac{2 G}{\left(\frac{u}{V_{S}}\right)\left(\frac{C}{R}\right)}\right)
\end{array}
$$

where $\mathrm{G}$ is non-dimensional circulation as given by $\mathrm{G}=\frac{\Gamma}{2 \pi R V_{s}}$, c is local chord length at each radius, $\mathrm{u}$ local inflow velocity, $\mathrm{C}_{\mathrm{L}}$ lift coefficient and $\mathrm{V}_{\mathrm{s}}$ : ship velocity at design condition. [10] The blade numbers are assigned based on the representation above, as shown in Fig. 5.

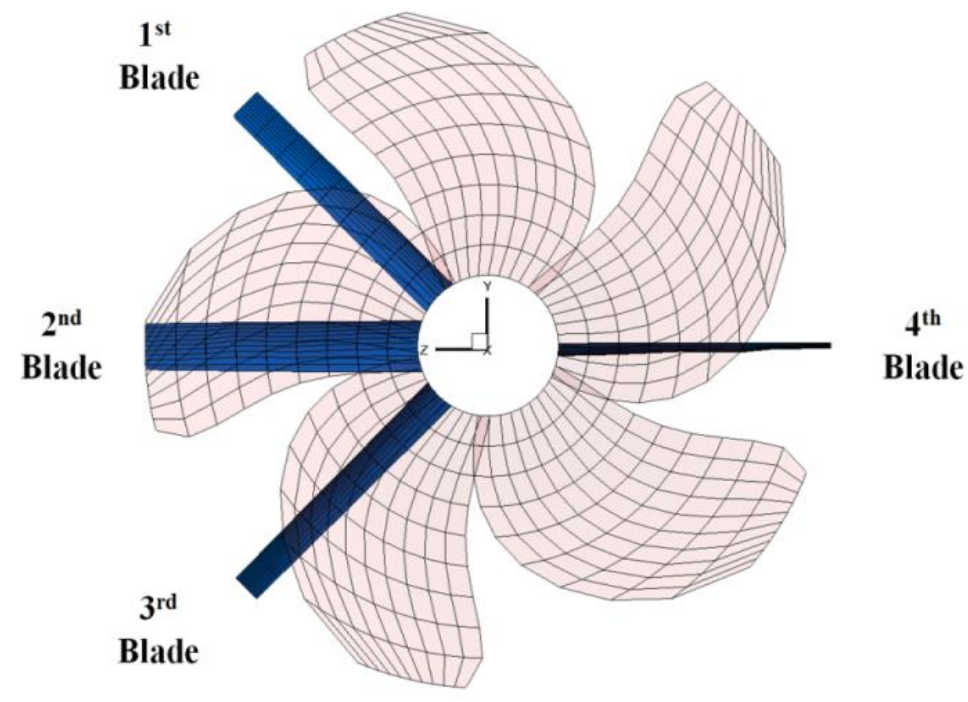

Fig. 5 Definition of blade number (looking upstream)

In the present study, the asymmetric pre-swirl stator proposed by Shin et al. [16] was used, as shown in Tables 1 and 2. The equivalent incident angle is verified, as shown in Fig. 6, using the potential-flow program, as explained above.

Table 1 Principle dimension of the asymmetric pre-swirl stator

\begin{tabular}{|c|c|}
\hline Section type & NACA 66 \\
\hline Scale ratio & 39.5 \\
\hline Model diameter (m) & 0.2 \\
\hline Skew $\left(^{\circ}\right)$ & 0.0 \\
\hline Rake $\left(^{\circ}\right)$ & 0.0 \\
\hline No. of blades & 4 \\
\hline
\end{tabular}


If the pitch angle (equivalent angle) is designed largely until the stall point th rotational energy of propeller can be recovered, however the drag of stator becomes large accordingly. Therefore, the reference of optimum equivalent angle is important in the design of pitch angle.

Table 2 Geometry of the asymmetric pre-swirl stator

\begin{tabular}{|c|c|c|c|c|c|c|c|c|c|c|c|}
\hline$r / R$ & 0.20 & 0.25 & 0.30 & 0.40 & 0.50 & 0.60 & 0.70 & 0.80 & 0.90 & 0.95 & 1.00 \\
\hline$C / D$ & 0.177 & 0.174 & 0.171 & 0.165 & 0.159 & 0.153 & 0.147 & 0.142 & 0.136 & 0.133 & 0.130 \\
\hline$f_{0} / C$ & - & - & - & - & - & - & - & - & - & - & - \\
\hline$t / D$ & 0.085 & 0.082 & 0.078 & 0.071 & 0.063 & 0.054 & 0.045 & 0.035 & 0.025 & 0.019 & 0.013 \\
\hline
\end{tabular}



Fig. 6 Radial circulation distribution on the stator blade

Kim et al. [12] confirmed that designing the pitch angle such that the maximum equivalent incidence angle is between $-13^{\circ}$ and $-14^{\circ}$ is generally most effective in improving the propulsion efficiency when a pre-swirl stator is installed on a low-speed full body ship. However, the drag of stator in case of container ships, which is the subject of this paper, increases significantly when large pitch angles are adopted. Therefore, the maximum angle is designated as $-12^{\circ}$, which is slightly lower than the equivalent incidence angle used for lowspeed full body ships [16]. Table 3 shows the pitch angles for each blade, and Fig. 7 shows the final 3D model.

Table 3 Comparison of pitch angle based on the stator type

\begin{tabular}{|c|c|c|}
\hline \multirow{2}{*}{ Blade No. } & \multirow{2}{*}{ Position $\left(^{\circ}\right)$} & Pitch Angle $\left(^{\circ}\right)$ \\
\cline { 3 - 3 } & & Constant Type \\
\hline 1 & 45 & 14 \\
\hline 2 & 90 & 19 \\
\hline 3 & 135 & 12 \\
\hline 4 & 270 & 2 \\
\hline
\end{tabular}


Validation of Optimally Designed Stator-Propeller System by EFD and CFD
Yong Jin Shin,

Moon Chan Kim, Jin Gu Kang

Hyeon Ung Kim, I Rok Shin

In the present study, the model delivered power at a design speed of $24 \mathrm{kts}$ is compared by changing the pitch angle of the stator by $\pm 2^{\circ}$ with respect to the pitch angle determined using the potential-flow program, as shown in Table 3. The pitch angle variations of $\pm 2^{\circ}$ are defined, as shown in Fig. 8. Table 4 shows each case according to the variation in the pitch angle.

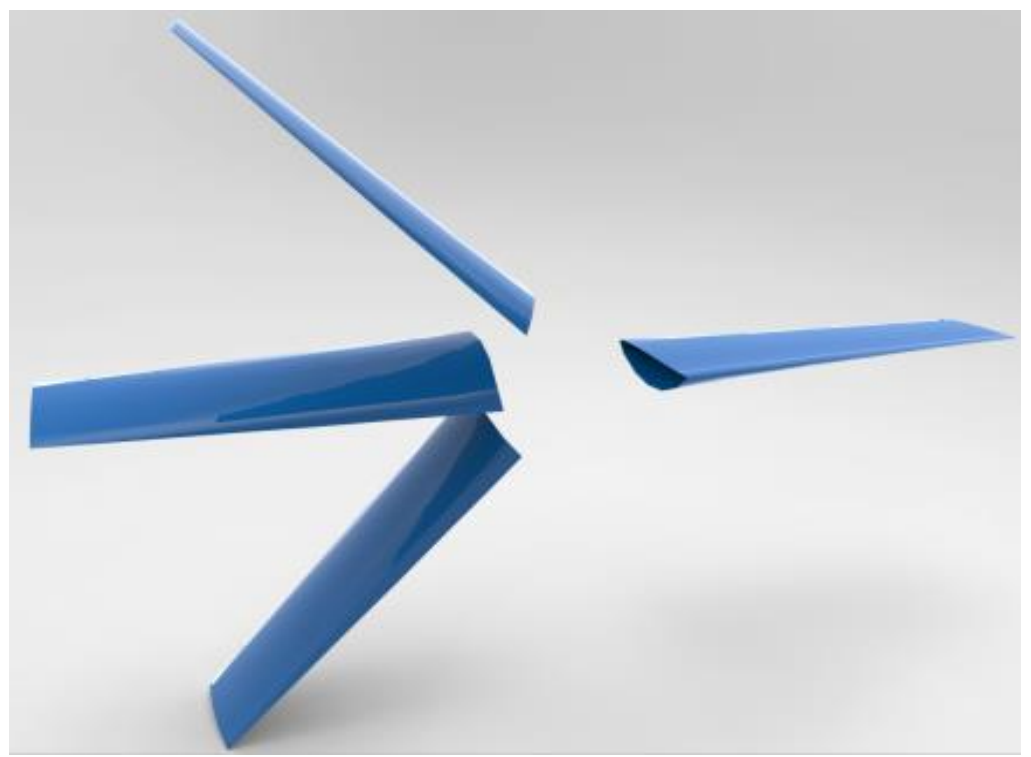

Fig. 7 3D modeling of the pre-swirl stator

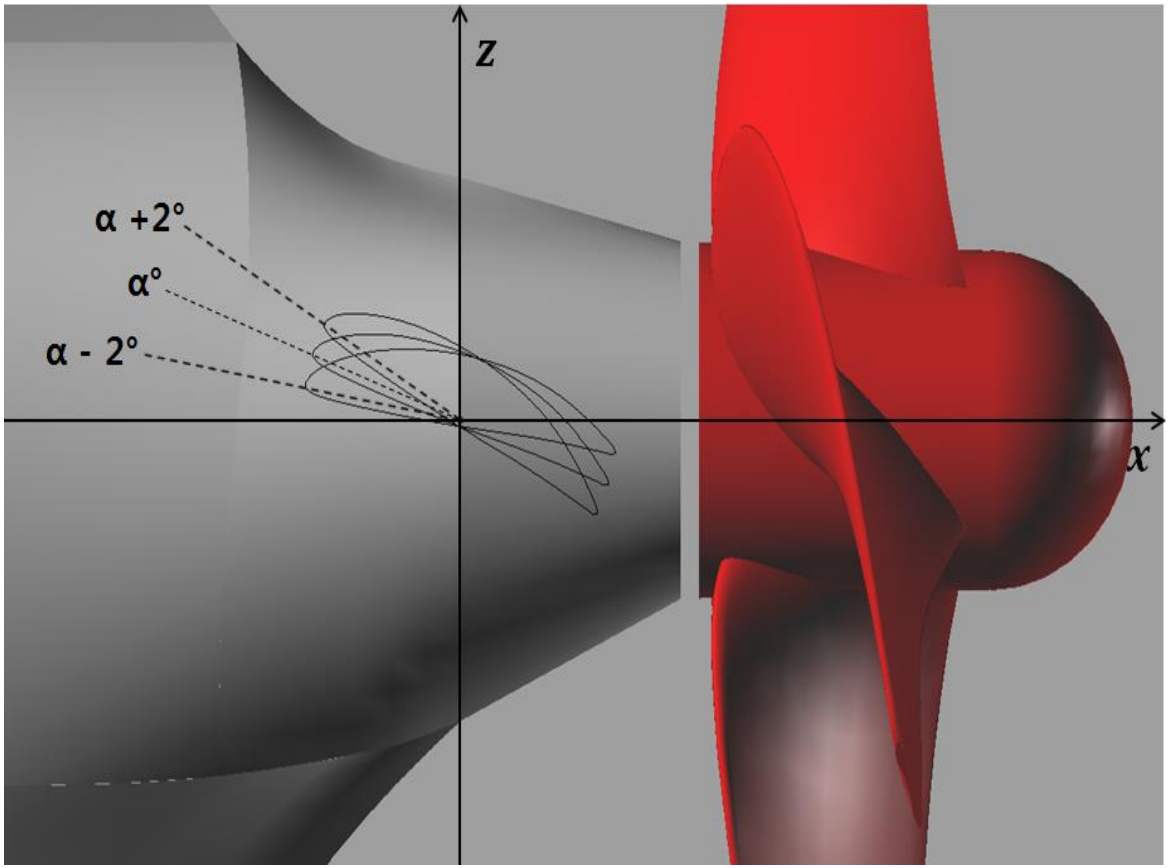

Fig. 8 Definition of pitch angle variation 
Table 4 Different cases based on the pitch angle of different blades

\begin{tabular}{|c|c|c|c|c|}
\hline \multirow{2}{*}{ Case No. } & \multicolumn{4}{|c|}{ Additional pitch angle $\left.{ }^{\circ}\right]$} \\
\cline { 2 - 5 } & $1^{\text {st }}$ Blade & $2^{\text {nd }}$ Blade & $3^{\text {rd }}$ Blade & $4^{\text {th }}$ Blade \\
\hline Case 1 & \multicolumn{2}{|c|}{ Optimally designed pitch angle using potential-flow program } \\
\hline Case 2 & +2 & 0 & 0 & 0 \\
\hline Case 3 & -2 & 0 & 0 & 0 \\
\hline Case 4 & 0 & +2 & 0 & 0 \\
\hline Case 5 & 0 & -2 & 0 & 0 \\
\hline Case 6 & 0 & 0 & +2 & 0 \\
\hline Case 7 & 0 & 0 & -2 & +2 \\
\hline Case 8 & 0 & 0 & 0 & -2 \\
\hline Case 9 & 0 & 0 & 0 & 0 \\
\hline
\end{tabular}

\section{Materials and Methods}

\subsection{Target ship}

The target ship used in the present study is a 3,600 TEU KRISO container ship (KCS), as shown in Fig. 9. The model ship was manufactured at a scale ratio of 39.5, considering the size of the towing tank at Pusan National University (PNU). The design speed of the model ship is $1.964 \mathrm{~m} / \mathrm{s}$. Table 5 shows the dimensions in detail.

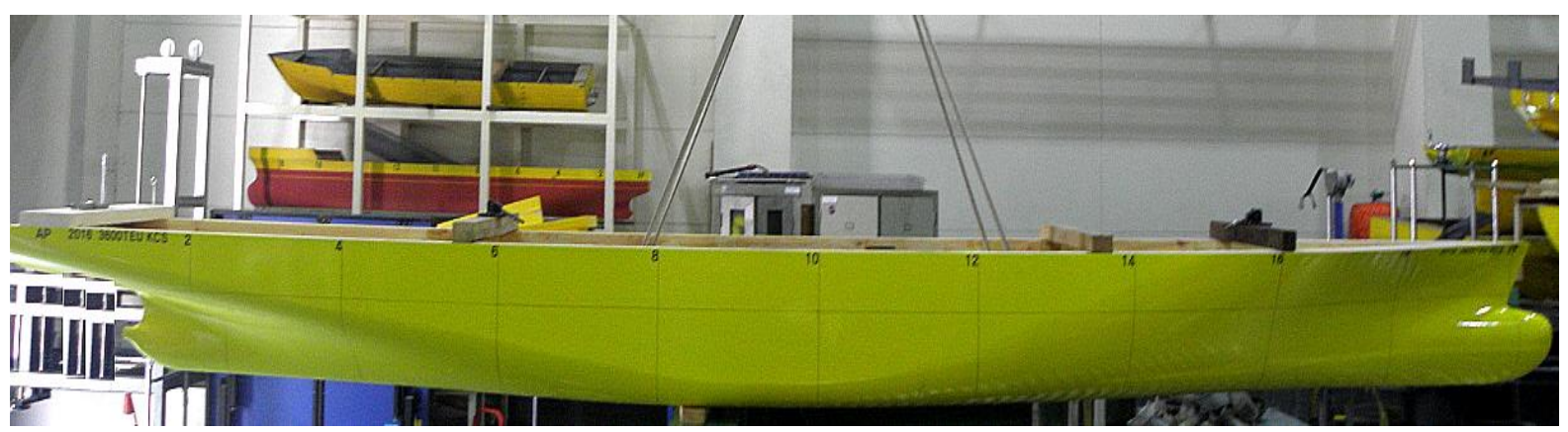

Fig. 9 3,600 TEU KRISO container ship model 
Table 5 Principal parameters of the target ship

\begin{tabular}{|c|c|c|}
\hline & Real ship & Model ship \\
\hline Length PP [m] & 230.00 & 5.82 \\
\hline Length WL [m] & 232.50 & 5.89 \\
\hline Breadth [m] & 32.20 & 0.82 \\
\hline Depth [m] & 19.00 & 0.48 \\
\hline Design draught [m] & 10.80 & 0.27 \\
\hline Block coefficient & 0.651 & 0.651 \\
\hline Design speed [m/s] & $12.346 \mathrm{~m} / \mathrm{s}$ & $1.964 \mathrm{~m} / \mathrm{s}$ \\
\hline Froude number & \multicolumn{2}{|}{0.259} \\
\hline Scale ratio & \multicolumn{2}{|}{39.5} \\
\hline
\end{tabular}

\subsection{Computational setup}

The commercial program STAR-CCM+ was used for the computations in this study. With the asymmetric pre-swirl stator attached to the target ship, a self-propulsion analysis was carried out at a design speed of $24 \mathrm{kts}$ for each case, as shown Table 4.

\subsubsection{Governing equations}

The RANS equations were used for this study, considering unsteady, incompressible, and viscous flows, which can be expressed as follows.

$$
\begin{gathered}
\frac{\partial u_{i}}{\partial x_{i}}=0 \\
\frac{\partial\left(\rho u_{i}\right)}{\partial t}+\frac{\partial\left(\rho u_{i} u_{j}\right)}{\partial x_{j}}=-\frac{\partial \rho}{\partial x_{i}}+\frac{\partial}{\partial x_{i}}\left[\mu\left(\frac{\partial u_{i}}{\partial x_{j}}+\frac{\partial u_{j}}{\partial x_{i}}\right)\right]+\frac{\partial}{\partial x_{i}}\left(-\rho \overline{u_{\imath} u_{j}}\right)
\end{gathered}
$$

where $u_{i}, \mathrm{p}, \mathrm{t}, \rho, \mu$, and $-\rho \overline{u_{\imath} \dot{u}_{j}}$ correspond to the speed, pressure, time, density, dynamic viscosity coefficient, and Reynolds stress tensor, respectively.

\subsubsection{Numerical method}

To resolve the coupling of the velocity and pressure, the semi-implicit method for pressure-linked equations consistent (SIMPLE) algorithm was used, and the realizable k- $\varepsilon$ model was chosen as the turbulence model. This improved the performance for the boundary layer separation flow with an adverse pressure gradient. In addition, a sliding interface moving mesh for direct rotation was used to rotate the propeller during the numerical analysis of the self-propulsion. Table 6 shows the details of the analysis conditions. 
Table 6 Analysis conditions

\begin{tabular}{|c|c|}
\hline Program & StarCCM+(Ver.9.04) \\
\hline Governing equation & Incompressible RANS \\
\hline Discretization & Cell-centered FVM \\
\hline Turbulence model & Realizable k- $\varepsilon$ model \\
\hline Wall function & Non-equilibrium \\
\hline Velocity-pressure coupling & SIMPLE algorithm \\
\hline Rotation method & $\begin{array}{c}\text { Sliding interface moving } \\
\text { mesh }\end{array}$ \\
\hline Yp+ & 100 \\
\hline Number of cells & approx. 5,000,000 \\
\hline Time step & $0.002 \mathrm{~s}$ \\
\hline Physical time & $50 \mathrm{~s}$ \\
\hline
\end{tabular}

The analysis method proposed by Choi et al. [17] was used for the performance comparison. The analysis results corresponding to both the propeller rotation speeds were used to determine the model total resistance $\left(R_{T M}^{S P}\right)$, thrust $\left(T_{M}\right)$, torque $\left(Q_{M}\right)$, and number of revolutions $\left(n_{M}\right)$ at the self-propulsion point. The wetted surface area was considered to determine the towing force (TF) corresponding to stator. To compare the performance, the delivered power of the model ship $\left(P D_{M}\right)$ was determined as follows.

$$
\begin{gathered}
\mathrm{TF}=R_{T M}^{S P}-T_{M} \\
\mathrm{P} D_{M}=2 \pi n_{M} Q_{M}
\end{gathered}
$$

\subsubsection{Boundary conditions and grid system}

Fig. 10 shows the boundary conditions employed in the present study. We used a velocity inlet condition for the entrance and outer boundary regions and a pressure outlet condition for the exit region. The computational domain was from mid-ship to $-1.5 \leq \mathrm{x} / \mathrm{Lpp} \leq$ 3.0 in the $\mathrm{x}$ direction, $-1.5 \leq \mathrm{Y} / \mathrm{L} \leq 1.5$ in the $\mathrm{y}$ direction, and $-1.5 \leq \mathrm{Z} / \mathrm{L} \leq 1.5$ in the $\mathrm{z}$ direction.



Fig. 10 Boundary condition 
Validation of Optimally Designed Stator-Propeller System by EFD and CFD
Yong Jin Shin,

Moon Chan Kim, Jin Gu Kang

Hyeon Ung Kim, I Rok Shin

The grid system was constructed with trimmer grids using automatic grid generation, which is provided in Star CCM+. Approximately 3,300,000 propeller cells are obtained around the ship using approximately 1,700,000 grids, as shown in Fig. 11. The volume-offluid (VOF) method was employed, which is widely used to analyze free-surface flow. This method is known to be robust with high validity and reliability for the analysis of complex nonlinear free-surface flows in relation to marine structures and wave-making problems of ships. Also the pressure or axial velocity field along a $y=0$ cut on the ship stern as shown in Fig. 12.
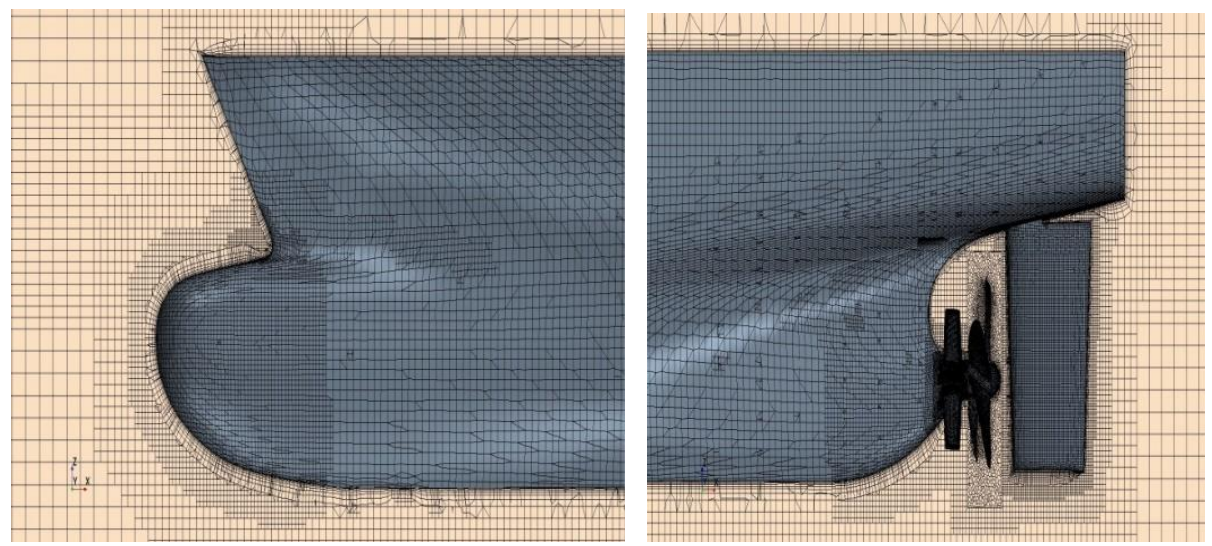

(a) bow and stern

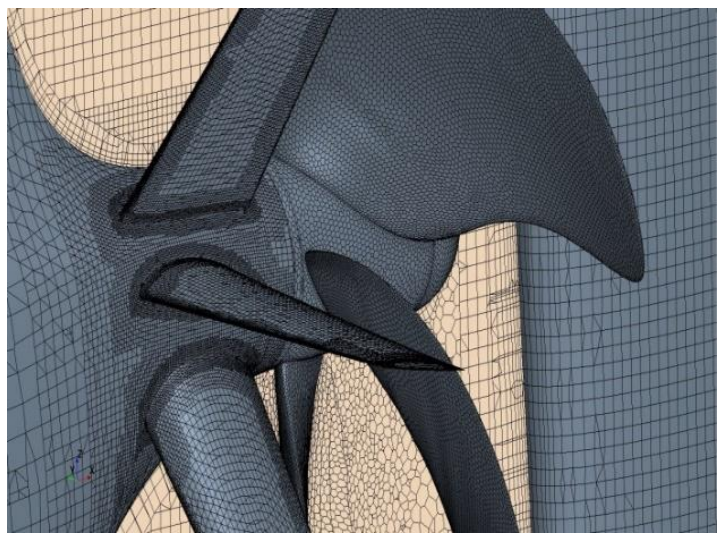

(b) stator and propeller

Fig. 11 View of the generated grids for the hull, propeller and pre-swirl stator

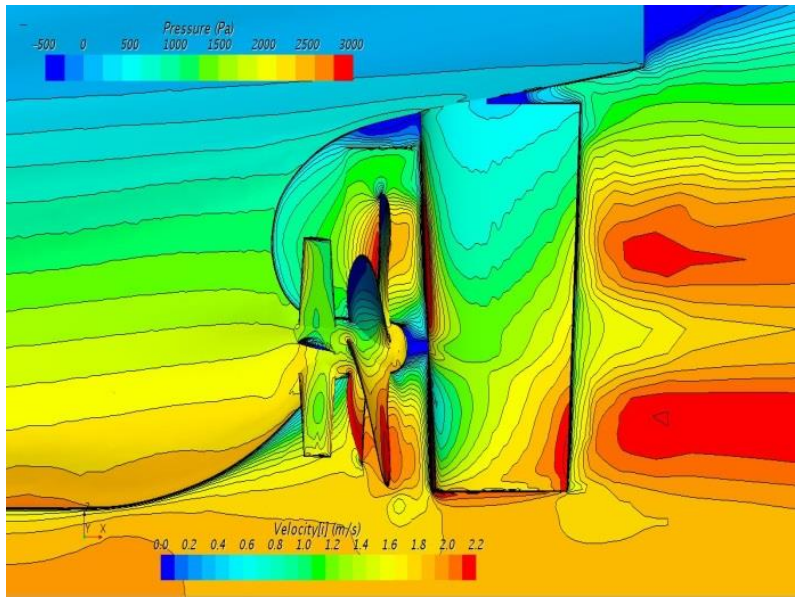

Fig. 12 The pressure or axial velocity field on the ship stern 
Yong Jin Shin,

Moon Chan Kim, Jin Gu Kang

Hyeon Ung Kim, I Rok Shin
Validation of Optimally Designed Stator-Propeller System by EFD and CFD

\subsection{Experimental setup}

Model testing was conducted in the towing tank at PNU. The length, width, and depth of the tank are $100 \mathrm{~m}, 8 \mathrm{~m}$, and $3.5 \mathrm{~m}$, respectively. The maximum speed of the towing tank carriage was $5 \mathrm{~m} / \mathrm{s}$.

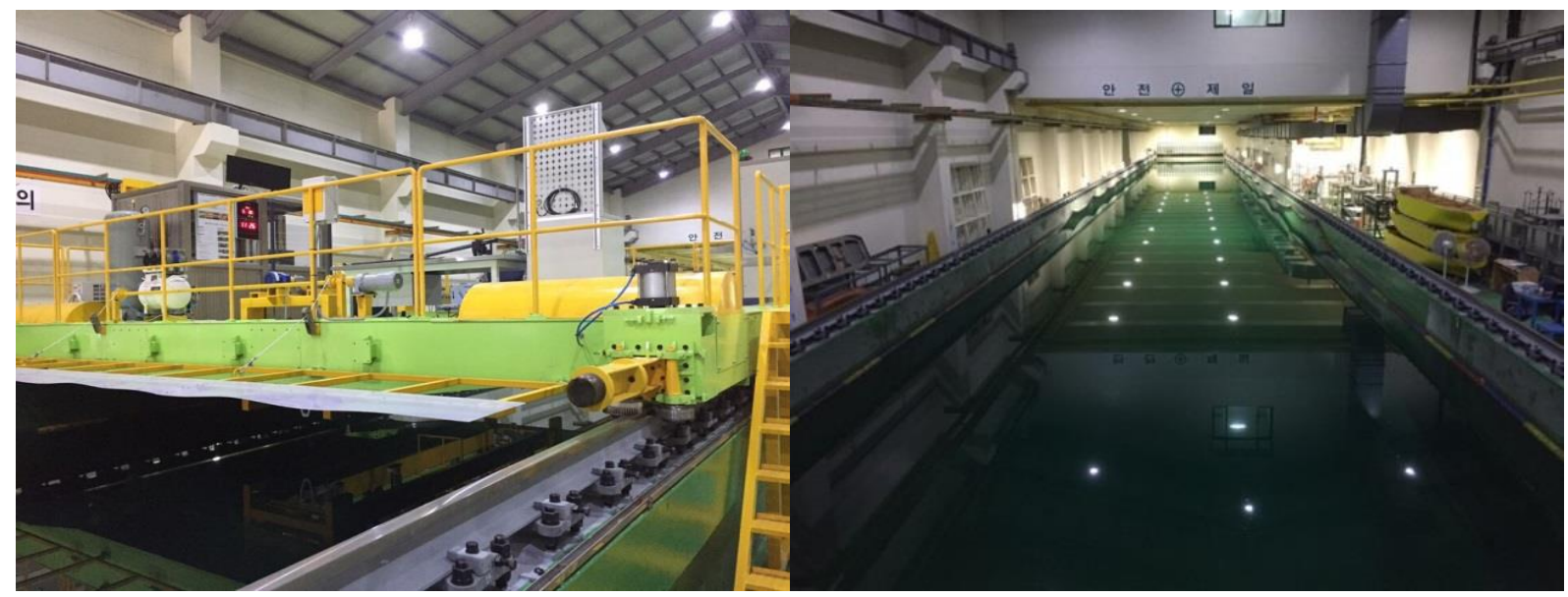

Fig. 13 Towing carriage and tank at PNU

The model size used for the model test was identical to that used for the numerical analysis. To verify the optimum pitch angle of the asymmetric pre-swirl stator, a controllablepitch-angle type is employed, making it possible to control the pitch angle, as shown in Fig. 14. Fig. 15 shows the experimental setup for the self-propulsion test.

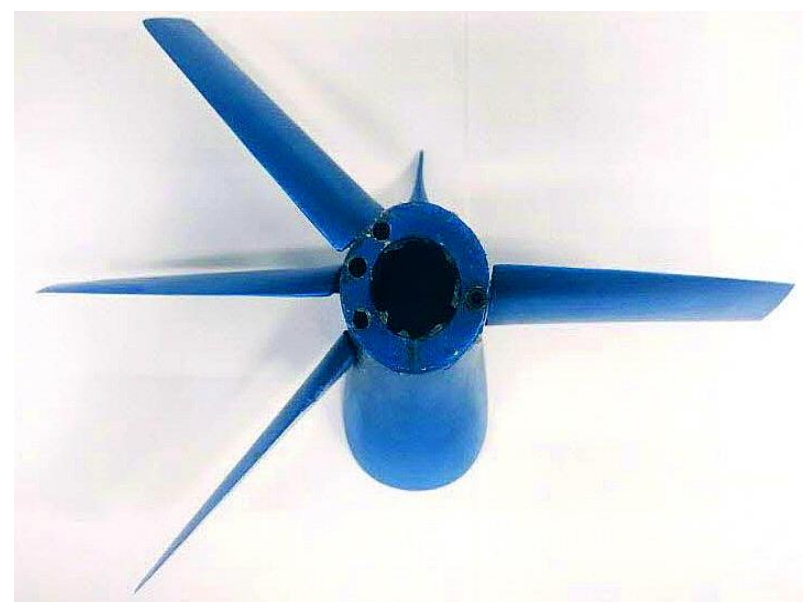

Fig. 14 Controllable pitch angle stator 




Fig. 15 Experimental setup for the self-propulsion test

The model tests were conducted in accordance with Froude's law of similarity. The measurement speed in the self-propulsion test was $24 \mathrm{kts}$.

\section{Results and discussion}

\subsection{Validation of experiment}

First, the bare hull experimental results have been compared with the Korea Research Institute of Ships \& Ocean Engineering (KRISO) model test results. Fig. 16 shows the comparison of the total resistance coefficient (CTM) at model scale of the PNU and KRISO model tests. There is a good correspondence between PNU and KRISO.



Fig. 16 Comparison of the CTM of model towing carriages and tanks at PNU and KRISO

First, the bare hull experimental results have been compared with the Korea Research Institute of Ships \& Ocean Engineering (KRISO) model test results. Fig. 15 shows the comparison of the total resistance coefficient (CTM) at model scale of the PNU and KRISO model tests as shown in the Fig. 15. there is a good correspondent between PNU and KRISO.

Relative error of total resistance coefficient (CTM) at model scale of the PNU and KRISO model tests as shown in Table 7. 
Table 7 Relative error of CTM between PNU and KRISO

\begin{tabular}{|c|c|c|c|}
\hline & $\begin{array}{c}\text { Bare Hull } \\
R_{T M}(N)\end{array}$ & $\begin{array}{c}\text { With Stator } \\
R_{T M}(N)\end{array}$ & Diff.(\%) \\
\hline PNU & 45.75 & 46.78 & 2.25 \\
\hline KRISO & 45.45 & 46.30 & 1.87 \\
\hline Diff. (\%) & -0.66 & -1.03 & \\
\hline
\end{tabular}

The validation of the present model test has been conducted by comparing the measured wake field with the computed result as shown in Fig 17. The results were similar in terms of the axial average velocity distribution and tangential-direction vector.
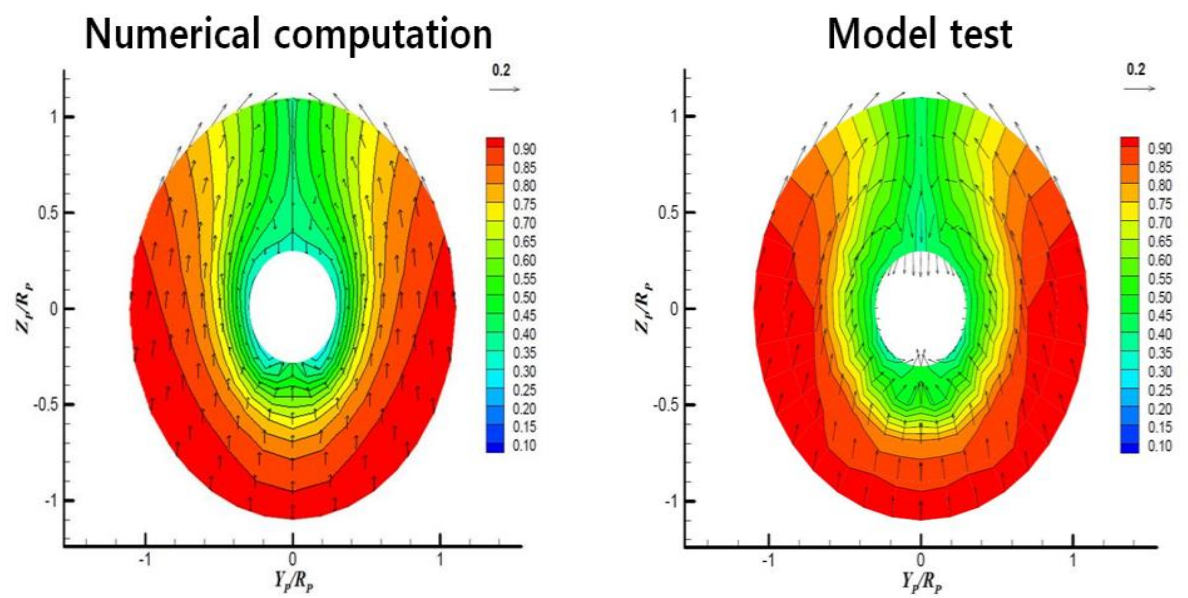

Fig. 17 Experimental and numerical wake distributions

The resistance and self-propulsion test result with and without stator were also compared with the CFD results whose results were very similar as shown in Table 8-9.

Table 8 Comparison of numerical and experimental resistance results

\begin{tabular}{|c|c|c|c|}
\hline & $\begin{array}{c}\text { Bare Hull } \\
R_{T M}(N)\end{array}$ & $\begin{array}{c}\text { With Stator } \\
R_{T M}(N)\end{array}$ & Diff.(\%) \\
\hline CFD & 45.75 & 46.78 & 2.25 \\
\hline EFD & 45.45 & 46.30 & 1.87 \\
\hline Diff. $(\%)$ & -0.66 & -1.03 & \\
\hline
\end{tabular}


Yong Jin Shin,

Moon Chan Kim, Jin Gu Kang Hyeon Ung Kim, I Rok Shin

Table 9 Comparison of numerical and experimental self-propulsion results

\begin{tabular}{|c|c|c|c|c|c|c|c|c|c|}
\hline & \multicolumn{3}{|c|}{$n_{M}(R P S)$} & \multicolumn{3}{c|}{$Q_{M}(N m)$} & \multicolumn{3}{c|}{$2 \pi n_{M} Q_{M}(W)$} \\
\cline { 2 - 10 } & Bare & With & Diff. & Bare & With & Diff. & Bare & With & Diff. \\
& Hull & Stator & $\%)$ & Hull & Stator & Hull & Stator & $(\%)$ \\
\hline CFD & 11.219 & 11.071 & -1.32 & 1.154 & 1.123 & -2.69 & 81.351 & 78.119 & -3.97 \\
\hline EFD & 10.900 & 10.650 & -2.29 & 1.174 & 1.155 & -1.62 & 80.403 & 77.288 & -3.87 \\
\hline $\begin{array}{c}\text { Difference } \\
(\%)\end{array}$ & -2.84 & -3.80 & - & 1.73 & 2.85 & - & -1.17 & -1.06 & - \\
\hline
\end{tabular}

The optimally designed pitch angle of the asymmetric pre-swirl stator was also verified through a numerical analysis and a model test, and the results are shown in Table 10.

Table 10 Comparison of numerical and experimental delivered horsepower according to pitch angles

\begin{tabular}{|c|c|c|c|c|c|c|}
\hline $\begin{array}{l}\text { Case } \\
\text { No. }\end{array}$ & $1^{\text {st }}$ Blade & $2^{\text {nd }}$ Blade & $3^{\text {rd }}$ Blade & $4^{\text {th }}$ Blade & $\begin{array}{c}2 \pi n_{m} Q_{m}[\mathrm{~W}] \\
\text { Numerical } \\
\end{array}$ & $\begin{array}{l}2 \pi n_{m} Q_{m}[\mathrm{~W}] \\
\text { Experimental }\end{array}$ \\
\hline 1 & \multicolumn{4}{|c|}{$\begin{array}{c}\text { Optimally designed pitch angle using } \\
\text { potential-flow program }\end{array}$} & 78.12 & 77.29 \\
\hline 2 & $+2^{\circ}$ & $0^{\circ}$ & $0^{\circ}$ & $0^{\circ}$ & 81.35 & 79.29 \\
\hline 3 & $-2^{\circ}$ & $0^{\circ}$ & $0^{\circ}$ & $0^{\circ}$ & 81.20 & 79.21 \\
\hline 4 & $0^{\circ}$ & $+2^{\circ}$ & $0^{\circ}$ & $0^{\circ}$ & 81.64 & 79.62 \\
\hline 5 & $0^{\circ}$ & $-2^{\circ}$ & $0^{\circ}$ & $0^{\circ}$ & 80.63 & 78.23 \\
\hline 6 & $0^{\circ}$ & $0^{\circ}$ & $+2^{\circ}$ & $0^{\circ}$ & 81.87 & 80.54 \\
\hline 7 & $0^{\circ}$ & $0^{\circ}$ & $-2^{\circ}$ & $0^{\circ}$ & 80.44 & 80.26 \\
\hline 8 & $0^{\circ}$ & $0^{\circ}$ & $0^{\circ}$ & $+2^{\circ}$ & 79.84 & 78.16 \\
\hline 9 & $0^{\circ}$ & $0^{\circ}$ & $0^{\circ}$ & $-2^{\circ}$ & 80.20 & 78.65 \\
\hline
\end{tabular}

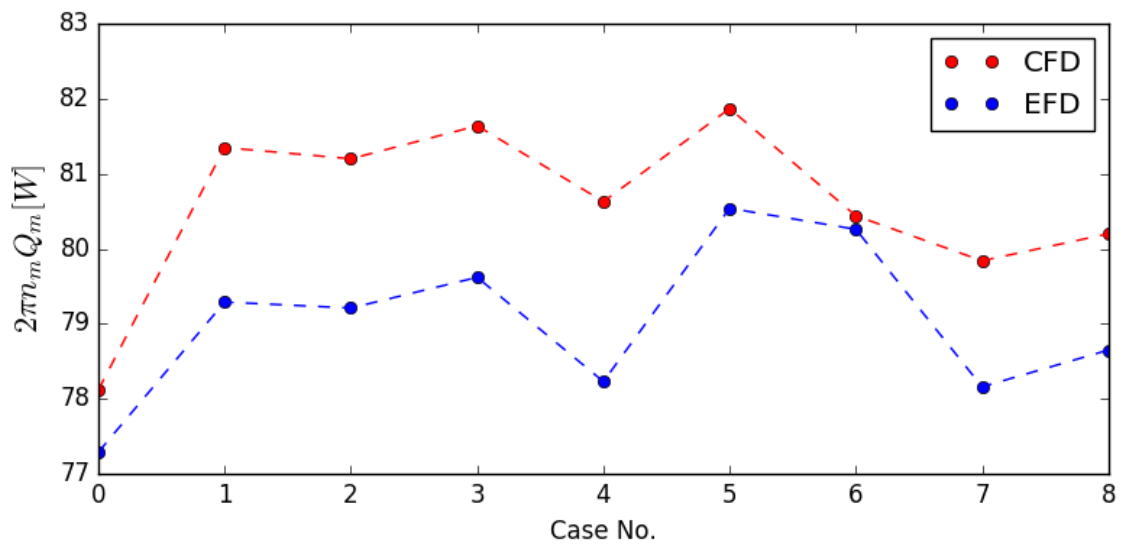

Fig. 18 Comparison of delivered power between CFD and EFD 
We compared the self-propulsion performances as represented by the delivered horsepower according to the variation in the stator pitch angle as calculated by both the model test and numerical computation. As shown in Table 9, the optimally designed pitch angle was verified by both methods, and their trends in resistance are qualitatively and quantitatively similar, although the viscous effect was considered as a flat plate in the potential-flow code. The potential-flow design program seems sufficiently accurate because the tangential flow potential-flow behavior of the stator is dominant in the flow field. There is no difference in resistance for each case, as shown in Table 11. Accordingly, The efficiency difference can be thought as the difference of delivered power can be compared at the model scale.

Table 11 Comparison of resistance results according to each case

\begin{tabular}{|c|c|c|}
\hline $\begin{array}{c}\text { Case } \\
\text { No. }\end{array}$ & $\begin{array}{c}\text { Numerical computation } \\
R_{T M}(N)\end{array}$ & Diff. (\%) \\
\hline 1 & 46.78 & - \\
\hline 2 & 46.90 & 0.26 \\
\hline 3 & 46.85 & 0.15 \\
\hline 4 & 46.91 & 0.28 \\
\hline 5 & 46.84 & 0.13 \\
\hline 6 & 46.91 & 0.28 \\
\hline 7 & 46.83 & 0.11 \\
\hline 8 & 46.80 & 0.04 \\
\hline 9 & 46.82 & 0.09 \\
\hline
\end{tabular}

We compared the wake distribution at a point $(\mathrm{x} / \mathrm{Lpp}=0.993)$ between the propeller and the rudder in Cases 1 and 6, as shown in Fig. 19. Overall, the rotational energy recovered in the hub area is higher in Case 1.
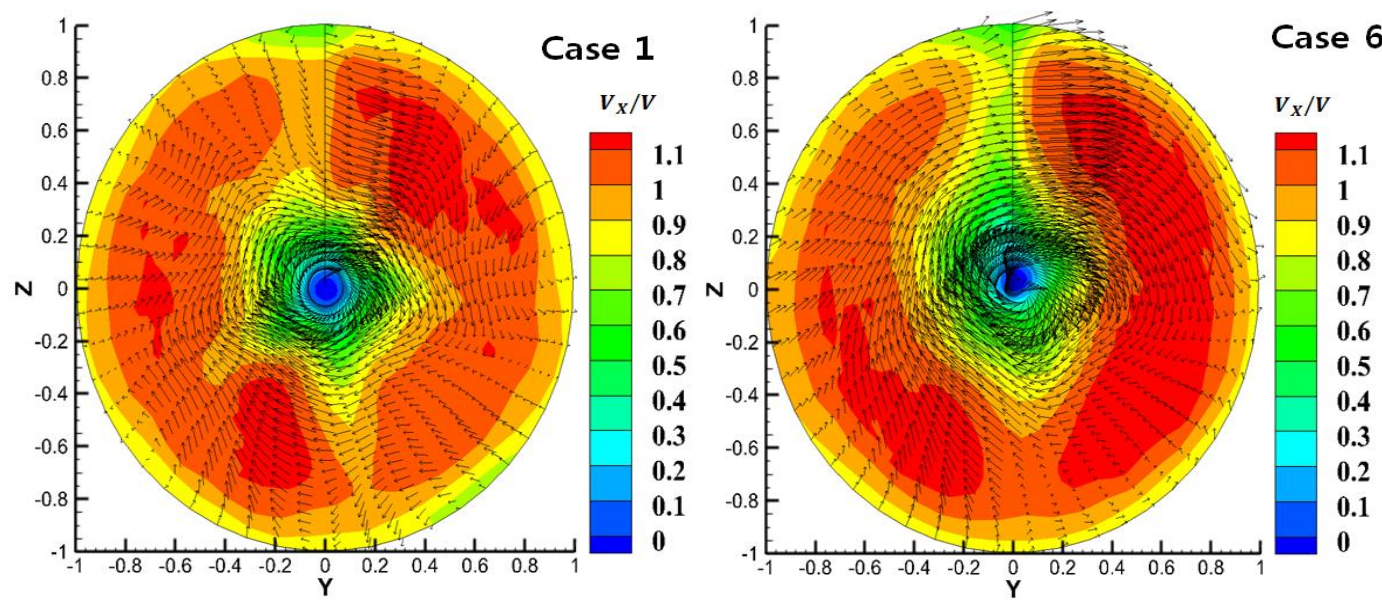

Fig. 19 Comparison of wake distributions at $\mathrm{x} / \mathrm{Lpp}=0.993$

Additionally, We compared the axial and tangential average velocity in Bare(Case 1) and w/PSS(Case 6) as shown in Fig. 20. Overall, the rotational energy recovered over each $\mathrm{r} / \mathrm{R}$ is higher in bare hull(Case 1$)$. 



Fig. 20 Comparison axial and tangential average velocity at $\mathrm{x} / \mathrm{Lpp}=0.993$

The streamline around the $2^{\text {nd }}$ blade is visualized in Fig. 21, which demonstrates that the flow escapes smoothly in Case 1. Meanwhile, in Case 6, a separation is observed. The difference between the delivered power of Cases 1 and 6 is also understood by this phenomenon.
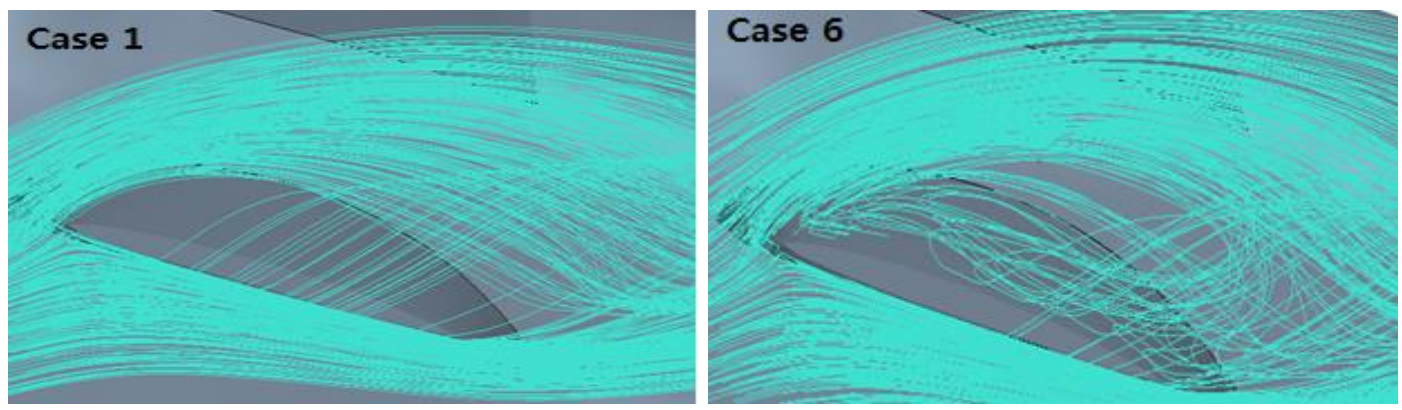

Fig. 21 Comparison of streamline at $2^{\text {nd }}$ blade

As the optimum pitch angle is rather sensitive to the propulsion efficiency, it should be carefully determined according to each ship wake and propeller.

\section{Conclusions}

An asymmetric pre-swirl stator is a device attached to the front of a propeller. It improves the efficiency by recovering the rotational energy and is a representative energysaving device that can be attached to any type of ship. For a non-uniform flow, the determination of the pitch angle of each blade is critical in the design of an efficient asymmetric pre-swirl stator.

In the present study, to verify the pitch angle of an asymmetric pre-swirl stator designed by using the potential-flow program, the optimal pitch angle was verified through numerical analysis and a model test. The model delivered power at a design speed of $24 \mathrm{kts}$ was compared by changing the pitch angle by $\pm 2^{\circ}$ with respect to previously designed angle.

In the numerical analysis, the model delivered power was compared through a selfpropulsion analysis by using the commercial code Star-CCM+. For the model test, the ship and asymmetric pre-swirl stator used in the numerical analysis were manufactured at the same scale and were tested in a towing tank at PNU. The manufactured model stator was a controllable-pitch-angle type to verify the optimum angle in the self-propulsion test. 
The results of both the numerical analysis and model tests showed that the pitch angle can be optimized using this model. The potential-flow design program seems sufficiently accurate because the tangential flow potential-flow behavior by the stator is dominant in the flow field.

In the near future, the full-scale performance with an asymmetric stator is expected to be investigated using CFD simulations. The difference between the optimum pitch angle of the model- and full-scale studies might not be so large that the tangential portion (potentialflow) becomes dominant, as shown in the present study.

\section{ACKNOWLEDGMENTS}

This work was supported by a National Research Foundation of Korea (NRF) grant funded by the Korea government (MSIP) through GCRC-SOP (No.2011-0030013).

\section{REFERENCES}

[1] Bazari, Z., and Longva, T., 2011, “Assessment of IMO-mandated energy efficiency measures for international shipping,” Lloyd's Register, London, UK.31 October 2011

[2] Carlton, J., 1994, "Marine Propellers and Propulsion. Third Edition," Butterworth-Heinemann, Great Britain.

[3] Djahida, Boucetta and Omar, Imine., 2019 "Numerical Simulation of The Cavitating Flow around Marine Co-Rotating Tandem Propellers” Brodogradnja.70( 1) pp. 43-57. https://doi.org/10.21278/brod70104

[4] Lee, J. T., Kim, M. C., Suh, J. C., Kim, S. H., Choi, J. K., 1992, "Development of Preswirl StatorPropeller System for Improvement of Propulsion Efficiency: a Symmetric Stator Propulsion System," J. Soc. Nav. Archit. Korea, 41(3), pp. 13-21.

[5] Lee, J. T., Kim, M. C., Van, S. H., Kim, K. S., Kim, H. C., 1994, "Development of a Preswirl Stator Propulsion System for a 300K VLCC,” J. Soc. Nav. Archit. Korea, 31(1), pp. 1-13.

[6] Kim, M. C., Lee, J. T., Suh, J. C., Kim, H. C., 1993, “A study on the Asymmetric Preswirl Stator System," J. Soc. Nav. Archit. Korea, 30(1), pp. 30-44.

[7] Yang, J. M., Lee, S. J., Kim, H. C., Suh, J. C., and Park, Y. M., 2000, "Effect of pre-swirl stator vane on the propeller hull interaction of a full ship," Proc. Annual Autumn Meeting, SNAK, Ulsan Korea.

[8] Yang, J. M., Kim K, Park, K. H., Kim, H. C., Suh, J. C., and Park, Y. M., 2001, "Effect of Pre-Swirl Stator Vane on the Propeller Hull Interaction," Proc. Annual Autumn Meeting, SNAK, Seoul, Korea.

[9] Kang, Y. D., Kim, M. C., Chun, H. H., 2004, “A Study on the Design of a Biased Asymmetric Pre-swirl Stator Propulsion System,” J. Soc. Nav. Archit. Korea, 44(3), pp. 13-21. https://doi.org/10.3744/SNAK.2004.41.3.013

[10] Kim, M. C., Chun, H. H., Kang, Y. D., 2004, "Design and Experimental Study on a New Concept of Preswirl Stator as an Efficient Energy-Saving Device for Slow Speed Full Body Ship,” Proc. SNAME, Washington, USA.

[11] Takekuma, K., Tsuda, S., Kawamura, A., and Kawaguchi, N., 1981, "Development of Reaction Fin as a Device for Improvement of Propulsive Performance of High Block Coefficient Ships," J. Soc. Nav. Archit. Jpn., 150, pp. 74-84. https://doi.org/10.2534/jjasnaoe1968.1981.150_74

[12] Kim, K. S., Kim, M. C., Wan, S. H., Sub, J. C., and Lee, J.T., 1994, “A Preswirl Stator-Propeller System as a Reliable Energy-Saving Device," Proc. Propeller/Shafting '94 Symposium, Virginia Beach, VA, USA.

[13] Stern, F., Kim, H. T., Zhang, D. H., Toda Y, Kerwin J., and Jessup S., 1994, "Computation of Viscous Flow around Propeller-Body Configurations: Series 60 Cb=0.6 Ship Model,” J. Ship Res., 38(2), pp. 137 157.

[14] Greeley, D. S. and Kerwin, J. E., 1982, "Numerical methods for propeller design and analysis in steady flow," Trans. SNAME, Vol. 90, pp. 415-453.

[15] Lee, C. M., Shin, Y. J., Kim, M. C., Choi, J. E., Chun, H. H., 2016, “Design of asymmetric pre-swirl stator for LNG carrier according to variation of stator shapes," J. Soc. Nav. Archit. Korea, 53(1), pp. 3744. https://doi.org/10.3744/SNAK.2016.53.1.37 
[16] Shin, Y. J., Kim, M. C., Kang, J. G., 2016, “Study on Performance of Asymmetric Pre-Swirl Stator according to Variations in Dimensions and Blade Tip Shape," J. Ocean Eng. Technol., 30(6), pp. 431-439. https://doi.org/10.5574/KSOE.2016.30.6.431

[17] Choi, J. E., Kim, J. H., Lee, H. G., Choi, B. J., Lee, D. H., 2009, “Computational prediction of ship-speed performance," J. Marit. Sci. Tech., 14(3), pp. 322-333. https://doi.org/10.1007/s00773-009-0047-4

Submitted: $\quad 04.12 .2018$.

Accepted: $\quad 22.08 .2019$.
Yong Jin Shin,

Moon Chan Kim (*corresponding author), kmcprop@pusan.ac.kr

Jin Gu Kang,

Hyeon Ung Kim,

I Rok Shin

Department of Naval Architecture and

Ocean Engineering, Pusan National 